\title{
Estado, indivíduo e liberdade: liberalismo e seguridade social
}

\section{State, Individual and Liberty: Liberalism and Social Welfare}

DOI: 10.12957/ek.2021.56691

\author{
Rodrigo Barbosa Gomes Benevides ${ }^{1}$ \\ Universidade Federal de São Carlos \\ rodrigobenevides23@gmail.com \\ https://orcid.org/0000-0002-0220-0503
}

\section{RESUMO}

Trata-se aqui de indicar que o Liberalismo Clássico, ao contrário da leitura usual, serve como quadro teórico para justificar intervenções estatais permanentes, seja em tempos de paz, seja em tempos de exceção. Posições como as de John Locke, John Stuart Mill e Thomas Paine indicam que a defesa da vida, da liberdade e da propriedade pressupõe um Estado atuante que, todavia, não entre em conflito com a preponderância do indivíduo no âmbito do jusnaturalismo. À luz da pandemia da Covid-19, o artigo pretende, portanto, elencar as razões pelas quais se deve advogar por uma ampliação do papel estatal ao se adotar medidas como, e.g., a Renda Básica Universal. Apesar da Renda Básica não ser sinônimo de intervenção estatal, o artigo pretende apenas apontála como uma possível medida que sirva como indício da necessidade da presença estatal em contextos emergenciais. Defende-se aqui, portanto, que a tradição do liberalismo e da filosofia política moderna como um todo é de suma importância na defesa de um Estado fundamentado na Seguridade Social. Para tanto, o artigo efetua um sobrevoo que tenta demonstrar - a partir de referências liberais clássicas - as conexões possíveis entre o liberalismo como fundamento filosófico de políticas públicas e as exigências que vieram à tona com a pandemia do coronavírus.

Palavras-chave: Estado. Liberalismo. Indivíduo. Liberdade. Utilitarismo. Filosofia Política.

\footnotetext{
${ }^{1}$ Doutorando em Filosofia pela Universidade Federal de São Carlos.
} 


\begin{abstract}
The paper indicates that Classical Liberalism, contrary to the usual reading, serves as a theoretical framework able to justify permanent state interventionism, whether in peace times or exceptional times. Authors such as John Locke, John Stuart Mill and Thomas Paine show that the defense of life, liberty and property presupposes an active State that, nonetheless, does not conflict with the preponderance of individual natural rights. In the light of the Covid-19 pandemic, the paper intends to list the reasons why an expansion of the role of the State should be advocated through the adoption of measures such as Universal Basic Income (UBI). Although UBI is not synonymous of state interventionism, the paper only tries to show it as a possible measure that points to the necessity of state presence in emergency contexts. Therefore, it is argued that the tradition of liberalism and modern political philosophy as a whole is of paramount importance in the defense of a Stated guided by the importance of Social Welfare. To this end, the paper offers an overview that tries to demonstrate - through several theoritical references - the possible connections between liberalism as a philosophical foundation of public policies and the demands that came to be with the coronavirus pandemic.
\end{abstract}

Keywords: State. Liberalism. Individual. Liberty. Utilitarianism. Political Philosophy.

\title{
INTRODUÇÃO
}

Em meio à crise da Covid-19, o governador de São Paulo, João Doria, fechou acordo com quatro operadoras de telefone para ter acesso aos dados do chamado SIMI (Sistema de Monitoramento Inteligente) ${ }^{2}$. Mais especificamente, o governo paulista pretendia utilizar apenas informações quantitativas referentes a mapas de calor que indiquem se há ou não aglomerações consideradas indevidas em ocasião da pandemia. Medida sensata e necessária para uns, exagero draconiano para outros. O que deve, então, prevalecer, a defesa da vida ou a liberdade individual? O núcleo de tal impasse pode assim ser definido: até que ponto o Estado de direito pode intervir sem mitigar as

\footnotetext{
${ }^{2}<$ https://g1.globo.com/sp/sao-paulo/noticia/2020/04/09/sp-usa-sistema-de-monitoramento-com-sinais-decelulares-para-localizar-aglomeracao-de-pessoas-no-estado.ghtml>. Acesso em 18 de dezembro de 2020.
} 
garantias individuais constitucionais? O cenário da medida do governo de São Paulo envolve a jurisprudência acerca da liberdade de locomoção e da preservação de dados pessoais, porém, a questão sobre os limites do Estado igualmente traz à tona o ponto que ocupa o centro das discussões de política macroeconômica no cenário de pandemia: como o Estado deve intervir de modo a resguardar a integridade material do indivíduo e não ceifar sua liberdade? A resposta, argumenta-se, pode se valer de elementos do Liberalismo Clássico, a fundamentação filosófica do direito constitucional ocidental. Contudo, trata-se aqui - ao contrário do usual quando se fala de liberalismo - de defender o incremento do papel do Estado e apontá-lo como imprescindível à segurança econômica e moral do indivíduo, a célula primordial do contrato social.

Tempos de exceção demonstram que o bom senso conclui a favor de uma intervenção estatal robusta não só em questões sanitárias, como nas de ordem econômica. Desse modo, a urgência de uma conjuntura de crise pode servir para a expansão de ações estatais por meio da implementação permanente de políticas econômicas como, por exemplo, a Renda Básica Universal, algo defendido por diversas figuras $^{3}$ como Thomas Paine ${ }^{4}$, John Stuart Mill ${ }^{5}$, Martin Luther King Jr. ${ }^{6}$ e, mais recentemente, o Papa Francisco. ${ }^{7}$ Portanto, argumenta-se aqui que a defesa do indivíduo (cerne do liberalismo) é justamente aquilo que impele a um Estado eficiente em tempos normais e, especialmente, em períodos de crise. Dito isso, o artigo se divide em dois momentos: primeiramente, examina-se as relações entre vigilância estatal e liberdade individual em tempos de crise; em seguida, demonstra-se que a intervenção governamental na economia está em harmonia com a obra de teóricos do liberalismo, apontando assim para a efetivação de políticas públicas como fator impreterível no amparo ao indivíduo.

\section{I.}

Dentro do âmbito do liberalismo, tomemos a ética utilitarista que compreende a sociedade como o contrato entre uma soma de indivíduos. É visando o homem,

$3<$ https://carnegieindia.org/2018/02/14/intellectual-heritage-of-universal-basic-income-pub-75502>. Acesso em 20 de janeiro de 2021.

${ }^{4}$ Cf. PAINE. Justiça Agrária (2019).

${ }^{5}$ Cf. MILL. Principles of Political Economy (2018).

${ }^{6}$ Cf. KING. Where do we go from here: Chaos or Community? (2010) 
singularmente falando, que deve partir qualquer formulação ética, jurídica e econômica ${ }^{8}$. O utilitarismo, portanto, está em harmonia com a visão políticoantropológica da modernidade na qual individualidades estabelecem $o$ convencionalismo do contrato social, ou seja, o Zoon Politikon aristotélico é abandonado pela hipótese do Estado de Natureza e, com isso, o jusnaturalismo moderno parte de direitos centrados no indivíduo que servem como princípios basilares para os condicionantes do contrato instaurador do Estado: "a comunidade é um corpo fíctício, composto pelas pessoas individuais que são consideradas como constituindo seus membros." ${ }^{\prime 9}$ Dito de outro modo, "O indivíduo é ele próprio um todo e é a soma desses pequenos todos que vai formar a comunidade." ${ }^{10}$ Em consonância com o liberalismo clássico, o utilitarismo também aponta as vantagens de uma economia onde prevalece a livre iniciativa, porém, tanto John Stuart Mill quanto Jeremy Bentham partem do pressuposto de que a convergência desregulada de interesses privados nunca será suficiente para assegurar a estabilidade contratual. Em outras palavras, "enquanto na esfera econômica a noção de uma fusão ou natural harmonização de interesses é aceita, no âmbito político o pensamento utilitário não prescinde de um agente normalizador externo." ${ }^{11}$ Como diria Thomas Hobbes, um pacto sem a espada tem o mesmo valor que palavras ao vento ${ }^{12}$, isto é, sem o Estado (monopólio da coerção) não há proteção e liberdade individual possível ${ }^{13}$. Em suma, um mínimo de centralização e coordenação de políticas sociais, econômicas e coercitivas é indispensável. Voltemos, pois, ao exemplo do governador de São Paulo.

\footnotetext{
${ }^{7}<$ https://www.cnbc.com/2020/04/13/pope-francis-it-may-be-the-time-to-consider-a-universal-basicwage.html $>$. Acesso em 18 de dezembro de 2020.

${ }^{8}$ Algo que, vale ressaltar, coaduna com os princípios do existencialismo, uma das duas últimas teorias éticas relevantes a terem surgido no ocidente, sendo o personalismo de Mounier a restante.

${ }^{9}$ BENTHAM. An Introduction to the Principles of Morals and Legislation (1948, p. 3).

${ }^{10}$ ARAÚJO. Bentham, o Utilitarismo e a Filosofia Politica Moderna (2006, pp. 273-274).

${ }^{11}$ CORREA. Utilitarismo e Moralidade: Considerações sobre o Indivíduo e o Estado (2012, p. 177).

12 "A finalidade última, causa final e desígnio dos homens (que amam naturalmente a liberdade e o domínio sobre os outros), ao introduzir aquela restrição sobre si mesmos sob a qual os vemos viver nos Estados, é o cuidado com sua própria conservação e com uma vida mais satisfatória. [...] Porque as leis da natureza (como a justiça, a eqüidade, a modéstia, a piedade, ou, em resumo, fazer aos outros o que queremos que nos façam) por si mesmas, na ausência do temor de algum poder capaz de levá-las a ser respeitadas, são contrárias a nossas paixões naturais, as quais nos fazem tender para a parcialidade, o orgulho, a vingança e coisas semelhantes. E os pactos sem a espada não passam de palavras, sem força para dar qualquer segurança a ninguém. Portanto, apesar das leis de natureza (que cada um respeita quando tem vontade de respeitá-las e quando pode fazê-lo com segurança), se não for instituído um poder suficientemente grande para nossa segurança, cada um confiará, e poderá legitimamente confiar, apenas em sua própria força e capacidade, como proteção contra todos os outros." (HOBBES, 1998, p. 84).
} 
No Artigo $5^{\mathrm{a}}$ da Constituição Federal de 1988 lê-se ${ }^{14}$ : "XV - é livre a locomoção no território nacional em tempo de paz, podendo qualquer pessoa, nos termos da lei, nele entrar, permanecer ou dele sair com seus bens". O detalhe crucial, é claro, diz respeito à especificação tempo de paz, algo que claramente não pode ser usado para caracterizar a pandemia da Covid-19. Mesmo que a ameaça não seja nem mesmo considerada um ser vivo, não é exagero afirmar que estamos, mutatis mutandis, em tempos de guerra. Claramente, então, partindo de um ponto de vista estritamente legalista, não há como se opor à decisão do governador em exercício de São Paulo, independente de sua posição no espectro político-ideológico. Porém, o $5^{\mathrm{a}}$ artigo ainda é deveras generalista. Vejamos, pois, a infração prevista no Artigo 268 do Decreto da Lei N. 2.848 de 7 de dezembro de 1940 que fala "Dos Crimes Contra a Saúde Pública"15: "Infringir determinação do poder público, destinada a impedir a introdução ou propagação de doença contagiosa. Pena - detenção, de um mês a um ano, e multa." Como diria Stuart Mill, “A única razão na qual o poder pode ser utilizado contra algum membro de uma comunidade civilizada é para prevenir o dano em outros." ${ }^{16}$ A liberdade individual, portanto, encontra limites legais quando um ato (no caso, o ir e vir) põe em risco o próprio fundamento do contrato, isto é, a preservação da vida. Qualquer noção jurídico-filosófica de liberdade bem fundamentada, portanto, sabe que medidas coercitivas são, em determinados casos, o meio mais eficiente de se garantir a liberdade individual enquanto tal, o que nos leva, a seguir, à noção de Vontade Geral conceitualizada por Rousseau. ${ }^{17}$

Apesar de não ser um autor normalmente associado ao liberalismo por conta da preponderância do valor da coletividade em sua obra (o que explica o maior apreço de pessoas politicamente à esquerda), Rousseau, não obstante, é um dos filósofos centrais do contratualismo e, assim como os demais pensadores da tradição, tratou de descrever um pacto social ideal que levasse em conta a contínua transformação e evolução da sociedade europeia ocidental. Em sua principal obra - Du Contrat Social - Rousseau oferece-nos a noção de Vontade Geral como norteador do contrato entre os indivíduos a

13 Cf. COSTA. Marta Nunes da. Revisiting Hobbes: On Freedom, Political Authority and Civil Disobedience (2018).

${ }_{14}<$ https://www.senado.leg.br/atividade/const/con1988/con1988 15.12.2016/art 5 .asp $>$. Acesso em 18 de dezembro de 2020.

${ }^{15}<$ http://www.planalto.gov.br/ccivil 03/decreto-lei/del2848.htm>. Acesso em 18 de dezembro de 2020.

${ }^{16}$ MILL. On Liberty (2001, p. 13). 
fim de garantir, ao máximo possível, a liberdade individual. No capítulo VI da referida obra, Rousseau enfatiza que seu contrato pretende beneficiar indivíduos, deixando clara a defesa da livre associação, o que demonstra - ao contrário do que muitos imaginam que a posição de Rousseau nunca foi a favor da abolição da propriedade privada, indicando assim sua proximidade com os demais contratualistas.

[...] encontrar uma forma de associação que defenda e proteja com toda força comum a pessoa e os bens de cada associado, e pela qual cada um, unindo-se a todos, não obedeça, entretanto, senão a si mesmo e permaneça tão livre como antes. Esse é o problema fundamental, ao qual o contrato social dá a solução. ${ }^{18}$

A despeito da óbvia defesa da liberdade individual, o princípio conceitual central do contrato proposto pelo autor de Emílio, no entanto, até hoje divide seus intérpretes sobre a possibilidade de esmagamento das liberdades individuais em nome de uma suposta vontade que representaria o todo. Bertrand Russell, por exemplo, chegou até mesmo a afirmar exageradamente que "Hitler é fruto de Rousseau."19 Apesar do histórico humanista e de viés à esquerda de Russell, o filósofo britânico antagoniza com Rousseau e enxerga na Vontade Geral uma possibilidade de justificativa filosófica ao cerceamento de liberdades. De fato, quando Rousseau defende - na célebre passagem ao final do Livro I do Contrato Social - que o corpo político deve, em relação ao indivíduo que se oponha à maioria, forçá-lo a ser livre, torna-se compreensível o terreno escorregadio que pode levar (por um caminho tortuoso, deve-se dizer) à justificação teórica do totalitarismo. Dito isso, a crítica de Russell, devemos admitir, possui seu teor de validez. Não por acaso, Marques $(2010$, p. 5) confirma que a análise de Russell não é assim de todo estranha ao considerarmos a magnitude de estudos voltados à obra do filósofo suiço: “Compreensivelmente, tal formulação tem provocado a perplexidade, e mesmo a hostilidade, de comentadores, que enxergam aí um sinal de que Rousseau endossa a submissão incondicional do indivíduo ao corpo coletivo." Vejamos, pois, a famigerada passagem de Rousseau.

Para que o pacto social, portanto, não seja uma fórmula vã, ele encerra tacitamente esse compromisso que, apenas ele, pode dar força aos outros, a saber, que quem quer que se recuse a obedecer à vontade geral será obrigado a isso por todo o corpo; o que significa apenas que será forçado a ser livre [ce

${ }^{17}$ Cf. ROUSSEAU. Jean-Jacques. Du Contrat Social (1966).

${ }^{18}$ ROUSSEAU. Du Contrat Social (1966, p. 360).

${ }^{19}$ RUSSELL. História da Filosofia Ocidental (2015, p. 243). 
qui ne signifie autre chose sinon qu'on le forcera d'être libre]; pois essa é a condição que, dando cada cidadão à pátria, o garante contra toda dependência pessoal; condição que constitui o engenho e o funcionamento da máquina política e que é a única capaz de tornar legítimos os compromissos civis, os quais, sem ela, seriam absurdos, tirânicos e sujeitos aos maiores abusos. ${ }^{20}$

A proposta de Rousseau, portanto, não significa a defesa de uma opressão do indivíduo, pelo contrário, a vontade geral é justamente o meio pelo qual o indivíduo torna-se livre, dada as exigências de uma vida inserida em um contrato que pressupõe o Estado. Como qualquer contratualista admitiria, a vida sob a égide do Estado, além dos óbvios benefícios, traz consigo coerções e determinadas restrições que, não obstante, existem para que a liberdade individual possa se dar no mais alto grau possível, mesmo que pontualmente determinados indivíduos não consigam compreender o telos destas ações estatais e acabem por sofrer sanções. ${ }^{21}$ A própria modernidade é marcada pelo caráter cada vez mais acentuado da preponderância do indivíduo, algo que não escaparia às formulações de Rousseau. Na mesma esteira, pode-se perceber posicionamento análogo em Immanuel Kant. Em Die Metaphysik der Sitten, o filósofo alemão expõe, em essência, a mesma argumentação oferecida por Rousseau (com a vantagem de ser redigida em termos menos propensos a interpretações ambíguas).

\begin{abstract}
A resistência que se opõe à obstrução de um efeito promove esse efeito e concorda com ele. Ora, tudo que é injusto é um obstáculo à liberdade segundo leis universais; a coerção, contudo, é um obstáculo ou resistência que afeta a liberdade. Por conseguinte, se um certo uso da liberdade é, ele próprio, um entrave à liberdade segundo leis universais (isto é, é injusto), então a coerção que a este se opõe, enquanto prevenção de uma obstrução da liberdade, está de acordo com a liberdade segundo leis universais, isto é, é justa. Ao direito, portanto, está logicamente ligada uma competência de coagir quem o viola. ${ }^{22}$
\end{abstract}

Com isso, como bem nos mostrou a situação da pandemia do coronavírus, a aplicação de uma Vontade Geral, quando bem efetuada e balizada na lei, é

${ }^{20}$ ROUSSEAU. Du Contrat Social (1966, p. 364).

21 Vale ressaltar que, mesmo quando Rousseau defende uma melhor distribuição de riquezas e propriedades de modo que ninguém precise chegar ao ponto de se vender para sobreviver, seu alvo sempre é a liberdade individual enquanto tal e não a igualdade per se. Toda crítica de Rousseau sobre as disparidades econômicas, no fundo, indicam a construção de um contrato onde a Vontade Geral prevaleça, o que é dificultado quando há uma concentração exacerbada de poder e riqueza. Como lembra Marques (2010, p. 13): "para Rousseau, a igualdade por si mesma não constitui um valor, mas é buscada porque a existência de grandes disparidades econômicas faz com que a vontade de grupos particulares termine por se impor à vontade geral, destruindo assim as condições para o exercício da liberdade. A liberdade plena é sempre o objetivo final, e não há, portanto, fundamento na usual alegação liberal de que Rousseau estaria disposto a sacrificá-la em nome de metas igualitárias."

${ }^{22}$ KANT. Die Metaphysik der Sitten (1914, p. 231). 
completamente razoável e necessária, dado o contexto. Se há um contágio de alta transmissibilidade que, sem a implementação de medidas de isolamento, resulta no colapso dos sistemas privado e público de saúde de um país, logo, o uso da máquina estatal para defender o direito natural da vida se justifica, mesmo que isso signifique medidas coercitivas como a obrigatoriedade do uso de máscaras estipulada no Rio de Janeiro $^{23}$, a detenção de pessoas no Ceará ${ }^{24}$ ou o fechamento de fronteiras como medida de contenção ${ }^{25}$. Infelizmente, representantes da população aproveitam sua posição temporária no Estado para atentar contra o interesse coletivo ao propagar ideias contrárias ao bom senso ${ }^{26}$ e ser omisso no combate à pandemia tanto no que diz respeito ao fornecimento de insumos hospitalares ${ }^{27}$ como na compra de vacinas ${ }^{28}$. Há até medidas provenientes da câmara legislativa federal que se colocam claramente contra as medidas sanitárias ${ }^{29}$. Em suma, o ponto central aqui, para nos determos ainda sobre Rousseau, não é que a liberdade do indivíduo seja ceifada por conta de um 'coletivismo' que anularia a liberdade individual, mas que a Vontade Geral age - por vezes pela coerção como na situação da pandemia - em benefício da totalidade dos participantes do contrato. ${ }^{30}$

Nos Estados Unidos ${ }^{31}$ e no Brasil ${ }^{32}$ encontramos diversos casos nos quais uma parcela considerável da população simplesmente se recusa a aceitar as medidas de

\footnotetext{
${ }^{23}<$ https://gauchazh.clicrbs.com.br/coronavirus-servico/noticia/2020/04/rio-de-janeiro-adotara-usoobrigatorio-de-mascaras-veja-outros-lugares-que-tambem-tomaram-essa-medidack9604olr004d017nbeit5fi9.html>. Acesso em 18 de dezembro de 2020.

${ }^{24}<$ https://g1.globo.com/ce/ceara/noticia/2020/04/19/tres-sao-presos-em-carreata-que-pedia-fim-daquarentena-e-intervencao-militar-em-fortaleza.ghtml>. Acesso em 18 de dezembro de 2020.

${ }^{25}<$ https://www.gov.br/casacivil/pt-br/assuntos/noticias/2020/abril/fechamento-de-fronteiras-governofederal-amplia-proibicao-de-entrada-no-brasil-por-meios-terrestres $>$. Acesso em 30 de janeiro de 2021.

${ }^{26}<$ https://valorinveste.globo.com/mercados/brasil-e-politica/noticia/2021/01/13/bolsonaro-sabotacombate-pandemia-diz-human-rights-watch.ghtml > . Acesso em 01 de fevereiro de 2021.

${ }^{27}<$ https://noticias.uol.com.br/saude/ultimas-noticias/redacao/2021/01/16/alertado-uma-semana-antesgoverno-federal-nao-conteve-crise-no-am.htm>. Acesso em 01 de fevereiro de 2021.

${ }^{28}<$ https://www.cnnbrasil.com.br/saude/2021/01/08/pfizer-diz-que-ofereceu-proposta-para-brasilcomprar-vacinas-em-agosto $>$. Acesso em 01 de fevereiro de 2021.

${ }^{29}<$ https://www.camara.leg.br/noticias/723567-projeto-acaba-com-uso-obrigatorio-de-mascaras-no-pais/>. Acesso em 01 de fevereiro de 2021.

${ }^{30}$ Como diz MARQUES (2010, p. 5), o fato de estar inserido no contrato faz do indivíduo um partícipe da Vontade Geral, o que implica na Vontade Geral ser traduzida em medidas coletivas que, no fundo, visam o bem-estar individual, mantendo assim, na medida do possível, a liberdade pré-contrato: "ao aceitar os vínculos que me obrigam frente à vontade geral, eu não estaria me submetendo a uma dominação alheia e externa, mas, dado que a vontade geral é a minha vontade, ou o que há de geral na minha vontade, eu continuaria obedecendo apenas à minha vontade e, por isso, permaneceria tão livre como era no estado pré-social."

${ }^{31}<$ https://www.theguardian.com/global/video/2020/apr/16/armed-protesters-demand-an-end-tomichigans-coronavirus-lockdown-orders-video $>$. Acesso em 18 de dezembro de 2020.
} 
quarentena e, na contramão da recomendação majoritária da comunidade médica mundial, defende que o retorno à normalidade deveria ocorrer o mais rápido possível. $\mathrm{O}$ caso brasileiro é ainda mais peculiar, já que a figura mais alta do executivo é uma das poucas lideranças mundiais a chegar em pleno janeiro de 2021 e oferecer um discurso contrário às medidas sanitárias, tornando-se assim verdadeira ferramente de propagação do vírus ${ }^{33}$. Os americanos, por sua vez, amparados pela segunda emenda de 1791, chegaram a sair armados em Michigan durante protestos em 2020, o que poderia ter levado a consequências funestas ${ }^{34}$. Como proceder, então, quando uma porção de indivíduos contraria ordens governamentais estipuladas para o seu próprio bem? O que fazer quando há pessoas que estão atentando contra o direito natural à vida (de si mesmas e das demais)? A maioria dos brasileiros, felizmente, concorda com a visão compartilhada por Kant, Rousseau e Stuart Mill: deve-se forçá-los a serem livres ou, mais especificamente, forçá-los a continuarem vivos. De acordo com o Datafolha ${ }^{35}$, $79 \%$ apoiam a punição a quem violar a quarentena. A Vontade Geral dos 79\% deve prevalecer, pois, apesar de não ser defendida pela totalidade de indivíduos, é ela que sustenta a liberdade individual enquanto tal. Ademais, para que a crítica do tipo oferecida por Russell não seja ignorada, a maioria compreende igualmente o perigo que nos ronda ao se impor uma coerção exageradamente incisiva, daí que apenas 3\% acreditam que o descumprimento deva ser punido com detenção, preferindo assim advertências verbais e multas pecuniárias. ${ }^{36}$ Portanto, temos aqui um meio-termo ideal que coaduna com o princípio utilitarista de intervenção estatal: "o Estado é cognitivamente privilegiado, sua Razão supera os juízos parciais dos indivíduos

\footnotetext{
${ }^{32}<$ https://jovempan.com.br/noticias/brasil/protesto-contra-quarentena-sao-paulo.html $>$. Acesso em $18 \mathrm{de}$ dezembro de 2020.

${ }^{33}$ A tese de que Jair Bolsonaro seja responsável direto pelo agravamento da pandemia é defendida por um grupo de ex-subprocuradores-gerais da República. A petição fundamenta-se no Artigo 267 do Código Penal onde se lê: "Art. 267 - Causar epidemia, mediante a propagação de germes patogênicos: Pena reclusão de dez a quinze anos. $\S 1^{\circ}$ - Se do fato resulta morte, a pena é aplicada em dobro. $\S 2^{\circ}$ - No caso de culpa, a pena é de detenção, de um a dois anos, ou, se resulta morte, de dois a quatro anos."

Cf. $\quad<$ https://noticias.uol.com.br/colunas/reinaldo-azevedo/2021/01/30/peticao-impecavel-a-pgr-acusabolsonaro-de-crime-que-rende-30-anos-de-cana.htm>. Acesso em 30 de janeiro de 2021.

${ }^{34}$ Infelizmente, como se sabe, a onda de anti-intelectualismo associada às posturas contrárias às medidas sanitárias confluiu com o conspiracionismo acerca da legitimidade da eleição presidencial americana, o que acarretou na morte de 5 pessoas durante a Invasão ao Capitólio de 6 de janeiro de 2021.

${ }^{35}<$ https://veja.abril.com.br/politica/79-dos-brasileiros-apoiam-punicao-a-quem-violar-quarentena-dacovid-19/>. Acesso em 18 de dezembro de 2020.

${ }^{36}$ Para que fique claro: a Vontade Geral de Rousseau não necessariamente deve coincidir com a vontade da maioria, como no caso da pesquisa supracitada.
} 
isolados e a ele cabe, portanto, incutir-lhes parâmetros para seus comportamentos." ${ }^{37}$ Luís Roberto Barroso, ministro do STF, manifestou na prática tal postura ético-jurídica quando - em seu voto acerca da obrigatoriedade da vacina contra a COVID-19 defendeu que cabe ao Estado proteger cada indivíduo "contra a sua desinformação ou a sua escolha equivocada, impondo a ele a imunização que irá preservar a sua vida ou a sua saúde. Esse é um dos raros casos em que o paternalismo se justifica, com o estado se sobrepondo à vontade individual." ${ }^{38}$ Desse modo, a partir da instanciação da postura utilitarista em medidas como a do ministro Barroso, o princípio da dignidade da pessoa humana é mantido e a liberdade (mesmo que temporariamente mitigada) prevalece, pois a vida é garantida. Todavia, é de comum acordo que a manutenção da vida via ações de quarentena e vacinação para achatamento da curva de transmissão é apenas uma parte do problema, o que nos leva ao ponto conseguinte: quais políticas econômicas devem ser adotadas para que a integridade material e moral do indivíduo prevaleça?

II.

1929 e 2008 marcam as piores crises econômicas a nível mundial dos últimos cem anos. Além da escala de impacto, ambas compartilham o fato de que só foram superadas devido ao intervencionismo crucial do Estado: New Deal, no caso da Grande Depressão; Emergency Economic Stabilization Act of 2008, na Crise dos Subprime. Já é certo que a atual crise é pior que a de $2008^{39}$ e, segundo certas interpretações, pode até superar a de $1929^{40}$, o que implica na incontestável necessidade de uma vigorosa intervenção governamental que, por sinal, já está em andamento por meio de medidas como a injeção de $\$ 2$ trilhões de dólares assinada por Donald Trump (o maior pacote de estímulo econômico da história dos Estados Unidos da América $)^{41}$ e o plano de combate à pandemia elaborado pelo governo Biden ${ }^{42}$.

\footnotetext{
${ }^{37}$ CORREA. Utilitarismo e Moralidade: Considerações sobre o Indivíduo e o Estado (2012, p. 180).

$38 \quad<$ https:/g1.globo.com/politica/noticia/2020/12/17/no-stf-barroso-vota-para-que-pais-nao-possamdeixar-de-vacinar-filhos-por-conviccoes-pessoais.ghtml $>$ Acesso em 18 de dezembro de 2020.

${ }^{39}<$ https://www.vox.com/2020/3/30/21191352/coronavirus-economic-crisis-2008-obama-administration $>$. Acesso em 18 de dezembro de 2020.

${ }^{40}<\underline{\text { https://fortune.com/2020/04/14/coronavirus-recession-predictions-great-depression-covid-19- }}$ lockdown-crisis-imf/>. Acesso em 18 de dezembro de 2020.

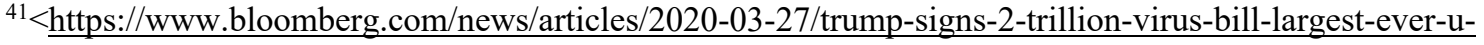
s-stimulus $>$. Acesso em 22 de Abril de 2020.

${ }^{42}<$ https://www.nbcnews.com/news/us-news/experts-praise-biden-s-covid-19-plan-warn-undoing-trump$\underline{\mathrm{n} 1255210}>$. Acesso em 30 de janeiro de 2021.
} 
É fato que a Grande Depressão foi pior que a crise de 2008 e, consequentemente, levou Franklin Delano Roosevelt a ações mais incisivas como quando, entre 1934 e 1941, o governo federal americano foi responsável pela criação direta de cerca de 12 milhões de empregos. ${ }^{43}$ Dito isso, não parece exagero vislumbrar soluções do porte de um New Deal, já que o FMI prevê que a crise da Covid-19 fará o PIB global recuar 3\%, colocando a economia internacional em sua pior situação desde 1929. ${ }^{44}$ O Brasil, por sua vez, provavelmente terá seu pior desempenho desde 1901 ao sofrer, presumidamente, um recuo de $4,5 \%$ de seu PIB. ${ }^{45}$ Com isso em mente, a ocasião abre uma janela de oportunidade para advogar por intermediações tão abrangentes e permanentes como a Previdência Social americana instituída em 1935, poucos anos após o Crash, enquanto o país ainda estava a lidar com sequelas econômicas. Medidas emergenciais, como se sabe, foram colocadas em prática, por exemplo, no Brasil ${ }^{46}$ e nos Estados Unidos ${ }^{47}$ com o envio de auxílios financeiros. Tal repasse direto de dinheiro, algo inconcebível para a maioria da população em períodos de normalidade, não encontrou sérias objeções dos políticos que compõem a totalidade do espectro político, ou seja, da esquerda à direita percebeu-se a concordância acerca da renda mínima como algo que deveria chegar às mãos da população. Porém, aberto o precedente, porque não mantê-la quando a pandemia for controlada? Nada a impede que a adotemos de modo permanente. As benesses da economia de mercado permitem-nos a idealização de um contrato no qual esteja garantido a inexistência de indivíduos em condições miseráveis. A ideia de uma Renda Básica Universal surge na Utopia (1516) de Thomas More ${ }^{48}$ e perpassa a tradição do liberalismo chegando até mesmo ao neoliberalismo de Milton Friedman que a chamou de Imposto de Renda Negativo, sem falar em figuras importantes da história do cristianismo como Martin Luther King Jr. e o Papa Francisco. $\mathrm{O}$ atual Papa, por sinal, é alguém que, repetidas vezes, traz atenção à problemática da desigualdade econômica e a urgência da situação planetária contemporânea, dedicando

\footnotetext{
${ }^{43}$ WOLFF. Democracy at Work (2012, p. 33).

${ }^{44}<$ https://g1.globo.com/economia/noticia/2020/04/14/com-coronavirus-economia-global-deve-ter-piordesempenho-desde-a-grande-depressao-diz-fmi.ghtml>. Acesso em 18 de dezembro de 2020.

$45 \quad<$ https://g1.globo.com/economia/noticia/2021/01/26/fmi-ve-nova-melhora-em-projecoes-para-pibglobal-brasil-deve-ter-encolhido-45percent-em-2020.ghtml $>$. Acesso em 30 de janeiro de 2021.

${ }^{46}<$ https://brasil.elpais.com/economia/2020-04-09/dois-milhoes-e-meio-de-brasileiros-recebem-a-rendaminima-do-coronavirus-no-primeiro-dia-de-pagamento.html > . Acesso em 18 de dezembro de 2020.

${ }^{47}<$ https://valor.globo.com/mundo/noticia/2020/03/18/eua-preparam-distribuicao-de-dinheiro-parapopulacao.ghtml $>$. Acesso em 18 de dezembro de 2020.

${ }^{48}$ Cf. MORE. A Utopia (2019).
} 
até mesmo sua última encíclia (Fratteli Tutti) ao tema. ${ }^{49}$ Portanto, a ideia de uma Renda Básica, além de ser uma proposta viável a curto prazo, faz parte do ideário ocidental e, inegavelmente, serviria como medida reformista de amparo crucial para a estabilidade e coesão social em um cenário pós-pandemia sem a necessidade da defesa de rupturas políticas ou econômicas drásticas que tendem ao desequilíbrio do pacto social ${ }^{50}$.

Ao privilegiar o indivíduo, a filosofia política liberal - ao contrário da visão costumeira que a retrata como uma espécie de apologética irrestrita de um laissez-faire absoluto - argumenta que é dever do Estado ser ator preponderante na sustentação econômica de cada pessoa participante do contrato. Mesmo John Locke é alguém que, de modo análogo a Rousseau, propõe limites à propriedade privada para que não haja um desequilíbrio exorbitante de riqueza. Lembremos, primeiramente, que a propriedade privada é um direito natural para Locke, daí que ela está para além dos consentimentos contratuais posteriores. A existência do Estado enquanto tal, portanto, perde sua legitimidade ao desrespeitar o direito à propriedade privada, definida por Locke em um duplo aspecto: todo indivíduo é proprietário de si no que diz respeito ao caráter de liberdade e autodeterminação da própria pessoa, além de ser o dono legítimo dos frutos de seu trabalho.

Embora a Terra e todos os seus frutos sejam propriedade comum a todos os homens, cada homem tem uma propriedade particular em sua própria pessoa; a esta ninguém tem qualquer direito senão ele mesmo. $O$ trabalho de seus braços e a obra de suas mãos pode-se afirmar, são propriamente dele. Seja o que for que ele retire da natureza no estado em que lhe forneceu e no qual o deixou, mistura-se e se superpõe ao próprio trabalho, acrescentando-lhe algo que pertence ao homem e, por isso mesmo, tornando-o propriedade dele. ${ }^{51}$

Em outras palavras, Locke defende que "O trabalho que tive em retirar coisas do estado em que estavam fixou minha propriedade sobre elas." ${ }^{2}$ Como defensor do jusnaturalismo, Locke argumenta que o estatuto natural da propriedade é um direito précontrato desvelado pelo uso adequado da própria razão: “essa lei da razão torna o cervo propriedade do índio que o abateu; permite-se que os bens pertençam aqueles que lhes

${ }^{49}<$ http://www.vatican.va/content/francesco/pt/encyclicals/documents/papafrancesco_20201003_enciclica-fratelli-tutti.html> Acesso em 31 de janeiro de 2021.

${ }^{50}$ Cf. PARIJS; VANDERBORGHT. Renda Básica: uma proposta radical para uma sociedade livre e economia sã (2018).

${ }^{51}$ LOCKE. Segundo Tratado sobre o Governo (2002, p. 38).

${ }^{52}$ LOCKE. Dois Tratados sobre o Governo (2005, p. 410). 
dedicou seu trabalho, mesmo que antes fossem direito comum de todos." ${ }^{53}$ Portanto, a terra e os demais recursos que existem no planeta são de direito comum a todos os homens até que o trabalho humano seja, de algum modo, incorporado aos bens retirados. Porém, se tal lógica fosse efetivada ao extremo, poucos homens estariam amparados juridicamente para dominar parcelas cada vez maiores. Para contornar tal problema, Locke propõe limitações à propriedade privada ao oferecer um critério que relaciona a delimitação da propriedade com a própria capacidade do trabalho humano individual. Com isso, do mesmo modo que o trabalho é aquilo que fundamenta a posse, este mesmo trabalho também se configura como parâmetro que limita a propriedade privada.

\begin{abstract}
A mesma lei da natureza que por este meio nos concede a propriedade, também limita essa propriedade. Deus deu-nos de tudo em abundância (1 Tm $6,17)$ é a voz da razão confirmada pela revelação. Mas até que ponto ele nolo deu? Para usufruirmos. Tanto quanto qualquer pessoa possa fazer uso de qualquer vantagem da vida antes que se estrague, disso pode, por seu trabalho, fixar a propriedade. $\mathrm{O}$ que quer que esteja além disso excede sua parte e pertence aos outros. [...] a extensão de terra que um homem pode arar, plantar, melhorar e cultivar e os produtos dela que é capaz de usar constituem sua propriedade. Mediante seu trabalho, ele, por assim dizer, delimita parte do bem comum. ${ }^{54}$
\end{abstract}

O bem comum, como se percebe, não é algo alheio à tradição liberal. A preponderância do indivíduo, curiosamente, é aquilo que fundamenta a preocupação da coletividade manifestada em princípios jurídicos e políticas econômicas. De fato, a tendência geral do liberalismo consiste em fazer frente ao Estado no intuito de salvaguardar o indivíduo, porém, a defesa de uma visão política liberal propriamente dita não se trata exatamente de uma discussão entre 'Estado mínimo' ou 'Estado máximo', mas Estado necessário. A devida posição liberal, portanto, está consoante, por exemplo, com a intervenção estatal que redistribui propriedades que não estejam alinhadas ao bem coletivo, algo codificado na CF-88 no conceito de Função Social da Propriedade, algo presente na obra de Locke: "se o fruto de seu plantio perecesse sem ser colhido e armazenado, esse pedaço da terra, não obstante sua cercadura, seria ainda visto como abandonado, e poderia ser a posse de qualquer outro." ${ }^{55}$ Logo, o direito à propriedade não é um valor que esteja acima da dignidade humana, já que o contrato

\footnotetext{
${ }^{53}$ Ibid., p. 411.

${ }^{54}$ Ibid., p. 412.

${ }^{55}$ Ibid., p. 419.
} 
justifica sua existência pela garantia da existência do indivíduo. Desse modo, a defesa da dignidade da pessoa humana, isto é, o princípio kantiano que norteia o estado democrático de direito de todos os governos liberais do ocidente, pressupõe um Estado presente e atuante em termos de intervenção econômica e social. A preocupação com o bem comum, portanto, é algo que materializa o fundamento jurídico kantiano que, lembremos, possui como pressuposto o imperativo categórico: "quando uma coisa tem um preço, pode pôr-se em vez dela qualquer outra equivalente; mas quando uma coisa está acima de todo o preço e, portanto, não permite equivalente, então tem ela dignidade" 56 . Portanto, todo indivíduo enquanto ser livre que trabalha e, pelo trabalho, adquire propriedade, está inserido em um contrato que legitima ações estatais no âmbito socio-econômico, especialmente em situações emergenciais como a encadeada pela pandemia da Covid-19. A incerteza econômica da paralisação forçada de diversas atividades econômicas deve servir como catalisadora de políticas públicas vigorosas. E para aqueles que, legitimamente, se preocupam com a possibilidade de uma hiperinflação no caso de uma elevação descontrolada dos gastos do Estado, basta lembrarmos do mote da - igualmente liberal - Teoria Monetária Moderna: a moeda de um país soberano é, em última instância, um registro de dívidas, ou seja, o Banco Central pode e deve imprimir dinheiro para financiar investimentos estatais em situações nas quais o mercado se prova ineficaz. ${ }^{57}$ Como admitiu Emmanuel Macron, presidente da França, a defesa de um Estado mais robusto é puro e simples bom senso, dada a urgência.

O que já mostra esta pandemia é que a saúde gratuita e nosso Estadoprovidência não são gastos e encargos, mas bem preciosos. (...) $\mathrm{O}$ que revela esta pandemia é que há bens e serviços que devem ser colocados fora das leis do mercado. Devemos retomar o controle, construir uma Europa soberana, uma França e uma Europa unidas. As próximas semanas e meses necessitarão de decisões de ruptura neste sentido. Eu as assumirei. ${ }^{58}$

Os franceses perceberam que a nacionalização de empresas, em muitas situações, vem a ser a melhor medida possível. O ministro das finanças, Bruno Le Maire, admitiu que a mão concreta do Estado é condição indispensável para a roda

\footnotetext{
${ }^{56}$ KANT. Fundamentação da metafisica dos costumes (1995, pp. 71-72).

${ }^{57}$ Cf. WRAY. Modern Money Theory: A Primer on Macroeconomics for Sovereign Monetary Systems (2015).

${ }^{58}<$ https://oglobo.globo.com/mundo/contra-trump-nacionalismos-macron-tenta-coordenar-resposta-da-uecoronavirus-24304796 $>$. Acesso em 18 de dezembro de 2020.
} 
continuar a girar: "Não hesitarei em utilizar todos os meios a meu alcance para proteger as grandes empresas francesas. Isto pode ser feito por meio da capitalização ou compra de participações. Inclusive posso usar o termo nacionalização se for necessário." 59 Do outro lado do Atlântico, Donald Trump não chegou ao ponto de cogitar a nacionalização de empresas, mas sinalizou que poderia usar o Ato de Produção de Defesa para, se for o caso, obrigar a General Motors e a Ford a produzirem respiradores necessários ao tratamento do coronavírus. ${ }^{60}$ A chamada Reconversão Industrial ${ }^{61}$, como se pode ver, é outro exemplo da necessidade do Estado como agente normalizador externo, ou seja, como se valer do mercado para suprir a escassez de equipamentos médicos no meio de uma pandemia a não ser por um mínimo de diretriz e planejamento centralizado? Ao invocar a reabertura da General Motors para produzir equipamentos hospitalares em seu Twitter (agora extinto após o incidente no capitólio) ${ }^{62}$, Trump serviu para demonstrar o papel perene do Estado como ferramenta superior de salvaguarda da coletividade. ${ }^{63} \mathrm{O}$ redirecionamento da atividade fabril de determinadas empresas, pois, torna-se um dever estatal para que o direito à vida seja mantido durante tempos invertidos, porém, a federalização do Estado-Nação, essencial para coordenar as ações de um território, constitui apenas o primeiro passo rumo a um esforço conjunto de nível planetário (algo hoje inquestionavelmente necessário, como bem demonstrou a pandemia). O alargamento da noção de um Estado atuante, pois, deve coadunar com a flagrante necessidade de uma internacionalização das esferas executivas (tanto em questões sanitárias como econômicas). Blocos econômicos, tratados e órgãos internacionais estão longe de ser novidade, mas trata-se aqui de algo nos moldes do que sugere Slavoj Žižek em seu artigo Coronavirus is 'Kill Bill'-esque blow to capitalism and could lead to reinvention of communism. ${ }^{64}$ Žižek, como o título indica, sugere que a situação atual pode ajudar no surgimento de um projeto de comunismo que consiga se desvencilhar

\footnotetext{
${ }^{59}<$ https://www.istoedinheiro.com.br/franca-disposta-a-nacionalizar-empresas-em-caso-de-necessidade/> . Acesso em 22 de Abril de 2020.

${ }^{60}<$ https://brasil.elpais.com/economia/2020-03-28/trump-invoca-uma-lei-da-guerra-da-coreia-paraobrigar-a-general-motors-a-fabricar-respiradores.html > . Acesso em 18 de dezembro de 2020.

${ }^{61}<$ https://www.conjur.com.br/2020-abr-11/mantoan-reconversao-industrial-medida-urgente2 $>$. Acesso em 18 de dezembro de 2020.

${ }^{62}<$ https://edition.cnn.com/2021/01/08/tech/trump-twitter-ban/index.html $>$ Acesso em 31 de janeiro de 2021.

${ }^{63}<$ https://epocanegocios.globo.com/Mundo/noticia/2020/03/epoca-negocios-trump-no-twitter-exige-quegm-e-ford-comecem-a-produzir-respiradores.html > Acesso em 18 de dezembro de 2020.

${ }^{64}<$ https://www.diariodocentrodomundo.com.br/vejo-um-novo-comunismo-distante-do-comunismohistorico-brotar-do-virus-diz-slavoj-zizek/>. Acesso em 18 de dezembro de 2020.
} 
das fracassadas tentativas históricas do séc. XX. Nossa tese, por outro lado, é mais modesta e alinha-se à social-democracia que, por definição, não visa rupturas sistêmicas: a urgência da situação deve ser utilizada para, com mais facilidade, nos levar a políticas econômicas liberais que são perfeitamente razoáveis, mas tidas como radicais ou minoritárias em tempos de paz, sendo a já aludida Renda Básica Universal a principal delas. No caso do Brasil, mais especificamente, a defesa de uma renda básica se torna ainda mais urgente tendo em vista o aumento do número de pessoas que vivem em condição de miséria, algo que deveria ser moralmente inaceitável no contexto ocidental $^{65}$. De qualquer modo, Žižek - para além do ideal de mudança revolucionária não admitido aqui - oferece sugestões exequíveis: sistemas nacionais de saúde pública e aumento do poder de atuação da OMS, levando-nos a uma rede de saúde planetária.

\begin{abstract}
O primeiro modelo, ainda vago, de tal coordenação global é a Organização Mundial da Saúde [...] Organizações como essa deveriam ter mais poder executivo. Os céticos ridicularizaram Bernie Sanders por sua defesa da cobertura universal da saúde pública nos EUA, mas o coronavírus não nos ensina a lição de que precisamos ainda mais do que isso, que devemos começar a criar algum tipo de rede GLOBAL de saúde pública? ${ }^{66}$
\end{abstract}

Esse tipo de postura que promove a cooperação internacional é algo que se tornou comum no desenvolvimento do pensamento ocidental. Em 1795, Kant já defendia o "direito da posse comunitária da superfície da Terra" e o ideal de um "direito cosmopolita". ${ }^{67}$ Não parece exagero, pois, afirmar que a pandemia possa servir como catalisador de novas proposições que nos aproximem da paz perpétua kantiana na qual o internacionalismo é pressuposto. Thomas Pogge, por exemplo, um dos principais teóricos da Renda Básica Universal, fundamenta a sua filosofia social na noção de direitos humanos como direitos naturais, o que implica em uma ética universalista ou cosmopolita que visa, em última instância, erradicar a miséria do planeta (um objetivo realizável se levarmos em conta o nível tecnológico em que hoje nos encontramos, mas que ainda aparece como ideal longínquo ao pensarmos nos inúmeros entraves políticos). ${ }^{68}$ Alguém como Trump, por exemplo, aproveitou a ocasião para transformar em ato sua aversão às entidades internacionais que, a seu ver, poderiam vir a solapar sua

${ }^{65}<$ https://www1.folha.uol.com.br/mercado/2021/01/brasil-comeca-2021-com-mais-miseraveis-que-hauma decada.shtml $>$. Acesso em 01 de fevereiro de 2021.

${ }_{66}<$ https://www.rt.com/op-ed/481831-coronavirus-kill-bill-capitalism-communism/> . Acesso em $22 \mathrm{de}$ Abril de 2020.

${ }^{67}$ KANT. À Paz Perpétua (1989, pp. 43-44). 
visão nacionalista de 'america first!' ${ }^{69}$ Não só recursos foram retirados da OMS, como também sobraram acusações de que a organização seria "centrada na China"70 por, supostamente, ter reservado menos atenção e cuidado aos Estados Unidos e ao restante do ocidente $^{71}$, transformando a crise virológica em mais uma ferramenta para a fomentação de seu populismo nacionalista que, em última análise, se apresenta como resposta ao suposto declínio dos valores ocidentais. Para tais defensores da tese da decadência do ocidente, a mera sugestão de uma expansão e/ou criação de órgãos internacionais com poder executivo só pode ser interpretada como tática de um "marxismo cultural globalista." ministro das Relações Exteriores do Brasil, Ernesto Araújo, ofereceu a seguinte conclusão:

\begin{abstract}
Não escapa a Žižek, naturalmente, o valor que tem a OMS neste momento para a causa da desnacionalização, um dos pressupostos do comunismo. Transferir poderes nacionais à OMS, sob o pretexto (jamais comprovado!) de que um organismo internacional centralizado é mais eficiente para lidar com os problemas do que os países agindo individualmente, é apenas o primeiro passo na construção da solidariedade comunista planetária. [...] Žižek explicita aquilo que vinha sendo preparado há trinta anos: o globalismo é o novo caminho do comunismo. O vírus aparece, de fato, como imensa oportunidade para acelerar o projeto globalista. Este já se vinha executando por meio do climatismo ou alarmismo climático, da ideologia de gênero, do dogmatismo politicamente correto, do imigracionismo, do racialismo ou reorganização da sociedade pelo princípio da raça, do antinacionalismo, do cientificismo. ${ }^{73}$
\end{abstract}

Araújo parece não estar familiarizado com o cosmopolitismo de $\mathrm{Kant}^{74}$ e erra ao não compreender (ou omitir) que o projeto universalista da diginidade da pessoa humana é de caráter iluminista e, no fim das contas, encontra suas raízes no judaísmo, no cristianismo e no desenvolvimento da cultura helênica, baluartes do ocidente. Em outro escrito, intitulado Trump e o Ocidente (2017), o chanceler brasileiro expõe de modo ainda mais claro o tipo de nacionalismo populista que, a nosso ver, deve ser combatido para, curiosamente, atingirmos justamente o fim desejado de manutenção

${ }^{68}$ Cf. POGGE. World Poverty and Human Rights: Cosmopolitan Responsibilities and Reforms (2007).

${ }^{69}<$ https://internacional.estadao.com.br/noticias/geral,trump-suspende-financiamento-dos-estados-unidosa-oms,70003271069>. Acesso em 18 de dezembro de 2020.

${ }_{70}<$ https://valor.globo.com/mundo/noticia/2020/04/07/trump-acusa-oms-de-ser-centrada-na-china.ghtml $>$. Acesso em 18 de dezembro de 2020.

$71<$ https://www.bbc.com/news/world-us-canada-52213439>. Acesso em 18 de dezembro de 2020.

72 ARAÚJO. Trump e o Ocidente (2017, p. 339).

${ }^{73}<$ https://veja.abril.com.br/mundo/chanceler-diz-que-mundo-enfrenta-comunavirus-apos-pandemia-decovid-19/>. Acesso em 18 de dezembro de 2020. 
dos valores ocidentais. Araújo recorda que no dia 06 de julho de 2017, em Varsóvia, naquilo que o Wall Street Journal classificou como seu "discurso definidor"75, Trump expôs o âmago daquilo mais próximo que se poderia chegar de uma "filosofia trumpista". ${ }^{76}$ Tal filosofia seria baseada, dentre outras coisas, na ideia de que "Trump quer reviver o Ocidente, e não estender o seu domínio. Trump não quer ocidentalizar as outras civilizações, quer apenas que deixem a civilização ocidental em paz para que ela possa recuperar-se e reencontrar o seu vigor."77, ou seja, não se trata de impor uma expansão militar ou cultural imperialista, mas sim de revigorar o Estado-Nação, ideal sintetizado no famigerado lema Make America Great Again que, analisado mais de perto, segundo Ernesto Araújo, significaria a luta primordial contra um inimigo que chega até mesmo a ultrapassar a ideologia comunista, a saber, o niilismo ou, em termos mais gerais, tudo aquilo que envolve as questões relacionadas aos projetos do 'globalismo', conceito trabalhado por autores como Joseph $\mathrm{Nye}^{78}$ e Olavo de Carvalho $^{79}$, sendo o último sabidamente uma das principais referências teóricas do ministro brasileiro.

Em Varsóvia, no dia 6 de julho de 2017, Trump pronunciou um discurso marcante em defesa do Ocidente. Um discurso que nenhum outro estadista no mundo hoje teria a coragem ou a capacidade de pronunciar. O tema central é a visão de que o Ocidente - concebido como uma comunidade de nações (e não como um amálgama indistinto sem fronteiras) - está mortalmente ameaçado desde o interior, e somente sobreviverá se recuperar o seu espírito; [...] Os EUA defenderam o Ocidente do comunismo e acharam que, quando o comunismo acabou, estava feito o trabalho, fim da história. Mas nada acabou. A partir dos anos 90 foi-se vendo que o niilismo (alimentado pelo marxismo cultural) tinha-se substituído ao inimigo comunista. $\mathrm{Na}$ verdade, pode-se argumentar que o comunismo soviético era apenas uma entre tantas máscaras desse niilismo fundamental que precede Lênin e Stálin, precede Marx, precede Nietzsche, que vem dos philosophes ateus anticristãos que prepararam a revolução francesa. ${ }^{80}$

Mais uma vez Araújo parece pecar ao não notar que, na verdade, o ateísmo era posição minoritária no iluminismo francês, sendo o deísmo à la Voltaire e Rousseau a

\footnotetext{
${ }^{74}$ KANT. Ideia de uma História Universal de um Ponto de Vista Cosmopolita (2010).

$75<$ https://www.wsj.com/articles/trumps-defining-speech-1499382025>. Acesso em 18 de dezembro de 2020 .

${ }^{76}<$ https://exame.abril.com.br/brasil/dizem-que-somos-trumpistas-o-que-e-um-pouco-verdade-diz-ernestoaraujo/>. Acesso em 18 de dezembro de 2020.

${ }_{77}$ ARAÚUO. Trump e o Ocidente (2017, p. 352).

$78<$ https://www.theglobalist.com/globalism-versus-globalization/>. Acesso em 31 de janeiro de 2021.

${ }^{79}$ CARVALHO. O Jardim das Aflições (2019).

${ }^{80}$ ARAÚJO. Trump e o Ocidente (2017, p. 326-347).
} 
tese dominante em quase todo salon littéraire ${ }^{81}$. E quando se fala do iluminismo em geral, basta pensar em figuras como Newton ${ }^{82}$, Locke ${ }^{83}$ ou Bacon ${ }^{84}$ para compreender que o pensamento de matiz iluminista não é equivalente a ateísmo. $\mathrm{O}$ anticlericalismo iluminista não rejeitava Deus, apenas o fideísmo frívolo e, principalmente, a influência da Igreja no Estado, princípio basilar do liberalismo. O iluminismo como um todo, portanto, não se caracteriza em oposição ao teísmo. De qualquer modo, após indicar o niilismo como inimigo-mor do ocidente, Ernesto Araújo evoca Martin Heidegger (de modo desvalido, vale ressaltar), apontando para um nacionalismo teocrático como resposta, além de mostrar-se em posição submissa em relação aos Estados Unidos.

\begin{abstract}
Trump: We want God [Nós queremos Deus]. Isso lembra a célebre afirmação de Heidegger no fim da vida: Nur noch ein Gott kann uns retten [Somente um Deus pode nos salvar.]. Esse "nós" que precisa desesperadamente de Deus, esse "nós" que apenas um Deus pode salvar, não é senão o Ocidente. [...] Trump parece bem mais otimista do que Heidegger, mas, em última instância, está em sua mensagem também o mesmo grito: agora só Deus. Nur noch ein Gott. Não será o desenvolvimento nem a tecnologia nem a justiça social nem a cooperação nem a sustentabilidade nem os direitos humanos que nos salvarão. Somente um Deus poderá salvar-nos, dar-nos sentido [...] Somente um Deus poderia ainda salvar o Ocidente, um Deus operando pela nação - inclusive e talvez principalmente a nação americana. Heidegger jamais acreditou na América como portadora do facho do Ocidente, considerava os EUA um país tão materialista quanto a União Soviética e incapaz da autopercepção metafísica indispensável à geração de um "novo começo", como ele dizia, essa refundação do Ocidente que repetiria em outros termos o primeiro começo gerado pelos antigos gregos. Talvez Heidegger mudasse de opinião após ouvir o discurso de Trump em Varsóvia, e observasse: Nur noch Trump kann das Abendland retten, somente Trump pode ainda salvar o Ocidente..$^{85}$
\end{abstract}

Com a derrota de Trump nas eleições disputadas com o democrata Joe Biden, o Itamaraty será forçado a adotar posturas que diminuam o impacto de decisões patéticas como a do diplomata Nestor Forster que, alinhado ao ocidentalismo vulgar de Ernesto Araújo, insistiu no discurso das suspostas fraudes eleitorais no sistema norte-americano, aconselhando ao governo brasileiro o não reconhecimento da vitória de Biden, fazendo do Brasil o último dos países que compõem o G-20 a parabenizar o político democrata. ${ }^{86}$ Ainda é cedo para conjecturar o papel do trumpismo na política americana

${ }^{81}$ Cf. REALE \& ANTISERI. História da Filosofia: Vol. 4 (2005).

${ }^{82}$ Cf. NEWTON. As Profecias do Apocalipse e o Livro de Daniel: As Raizes do Código da Bíblia (2011).

${ }^{83} \mathrm{Cf}$. LOCKE. The Reasonableness of Christianity (2014).

${ }^{84}$ Cf. BACON. Novo Órganon (2014).

${ }^{85}$ ARAÚJO. Trump e o Ocidente (2017, p. 355-356).

${ }^{86}<$ https://internacional.estadao.com.br/noticias/geral,embaixador-nos-eua-orientou-brasil-a-nao-admitirtriunfo-de-biden,70003553381>. Acesso em 31 de janeiro de 2021. 
e mundial do porvir, porém, é impreterível aos interesses brasileiros o afastamento de posições contraproducentes como as do atual chanceler brasileiro que ofereceu nada além de posicionamentos desastrosos que apenas alimentam um tipo de acirramento político-ideológico ${ }^{87}$ que, no caso de Trump ${ }^{88}$, acabou aumentando o sentimento antiinstitucional que desembocou na invasão do Capitólio. De qualquer modo, o fato é que a derrocada eleitoral de Trump foi de suma importância para a manutenção da vitalidade do Ocidente, este modo de ser originário da grécia que deve ser mantido não pela defesa de ideologias e líderes políticos que colocam em risco a democracia, mas pela propagação e concretização contemporânea dos ideais iluministas ${ }^{89}$ que perpassam as constituições ocidentais e sintetizam o que há de melhor da herança combinada de gregos, romanos, judeus e cristãos. Para que fique claro: conservadorismo per se, obviamente, é crucial para o funcionamento saudável de qualquer democracia ocidental. Não há, a nosso ver, possibilidade de desenvolvimento político sem a presença de figuras que mantenham viva a tradição manifestada em figuras como Edmund Burke ${ }^{90} \mathrm{e}$ Russel Kirk ${ }^{91}$, porém, assim como a esquerda progressista pode abalar o funcionamento democrático normal ao se valer de ações revolucionárias anti-iluministas, a direita conservadora democrática também pode vir a prejudicar a organização social ao dar voz e palco para reacionários que, curiosamente, estão na contramão do avanço éticojurídico que sustenta o ocidente. Portanto, talvez, ao familiarizar-se com a história do liberalismo, do iluminismo e da ética judaico-cristã, o chanceler perceba que os valores ocidentais podem ser mantidos com ideias ocidentais: princípio da dignidade da pessoa humana, seguridade social com um Estado atuante e cooperação cosmopolita.

\section{CONCLUSÃO}

O Liberalismo Clássico deve ser diferenciado do neoliberalismo consolidado no Consenso de Washington em 1989. A limitação da propriedade privada proposta por

\footnotetext{
${ }^{87}<$ https://www.oantagonista.com/mundo/ernesto-araujo-joga-para-a-claque/>. Acesso em 01 de fevereiro de 2021.

${ }^{88}<$ https://www.brookings.edu/blog/techtank/2021/01/11/the-role-of-misinformation-in-trumpsinsurrection/>. Acesso em 01 de fevereiro de 2021.

${ }^{89}$ PINKER. Enlightenment Now: The case for Reason, Science, Humanism and Progress (2019).

${ }^{90}$ BURKE. Reflexões sobre a Revolução na França (2014).

${ }^{91}$ KIRK. A Mentalidade Conservadora (2020).
} 
John Locke, o papel imprescindível do Estado defendido pelo utilitarismo de Bentham e Stuart Mill, o princípio kantiano da dignidade da pessoa humana e a crescente popularização de medidas como a Renda Básica Universal apontam que os princípios filosóficos do liberalismo podem fundamentar uma ampliação da ação estatal que, concomitantemente, se alinhe à necessidade - demonstrada pelas proporções que tomaram a crise desencadeada pela pandemia da Covid-19 - da incrementação da colaboração supranacional que, gradualmente, possa vir a aproximar-nos do ideal kantiano de paz perpétua que, pelo comércio e cooperação científica contínua entre as nações, nos encaminhe à diminuição de conflitos bélicos e à solidariedade cosmopolita universalista, isto é, "um contrato dos povos entre si". ${ }^{92}$

\section{Referências bibliográficas}

ARAÚJO, Cícero. Bentham, o Utilitarismo e a Filosofia Política Moderna, in A. Boron (ed.), Filosofia política moderna: de Hobbes a Marx, Buenos Aires/São Paulo, Clacso/USP, 2006.

ARAÚJO, Ernesto Henrique Fraga. Trump e o Ocidente. In: Cadernos de Política Exterior, Ano III, N. 6, 2017, pp. 323-357.

BACON, Francis. Novo Órganon. São Paulo: Edipro, 2014.

BENTHAM, Jeremy. An introduction to the principles of morals and legislation. Nova York, Hafner Press, 1948.

BURKE, Edmund. Reflexões sobre a Revolução na França. São Paulo: Edipro, 2014.

CARVALHO, Olavo de. O Jardim das Aflições: De Epicuro à Ressureição de César. Ensaio sobre o Materialismo e a Religião Civil. Campinas: Vide Editorial, 2019.

CORREA, Lara Cruz. Utilitarismo e Moralidade: Considerações sobre o indivíduo e o Estado. Revista Brasileira de Ciências Sociais, Vol. 27, N. 79, Junho/2012, pp. 173-186.

${ }^{92}$ KANT. À Paz Perpétua (1989, p. 41). 
COSTA, Marta Nunes da. Revisiting Hobbes: On Freedom, Political Authority and Civil Disobedience. João Pessoa: Revista Aufklärung, Vol. 5, N. 2, Maio-Agosto, 2018, pp. 59-74.

HOBBES T. Leviathan. Oxford: Oxford World's Classics, 1998.

KANT, Immanuel. Die Metaphysik der Sitten. In: Kant's gesammelte Schriften, vol. VI, Akad. Ausgabe, Berlim, 1914.

. Fundamentação da metafísica dos costumes. Tradução de Paulo Quintela. Porto: Porto, 1995.

. Ideia de uma História Universal de um Ponto de Vista Cosmopolita. São Paulo: Martins Fontes, 2010. . À Paz Perpétua. Porto Alegre: L\&PM, 1989.

KING, Martin Luther. Where do we go from here: Chaos or Community? Boston: Beacon Press, 2010.

KIRK, Russel. A Mentalidade Conservadora. São Paulo: Editora É Realizações, 2020.

LOCKE, John. Dois tratados sobre o governo. São Paulo: Martins Fontes, 2005. . Segundo tratado sobre o governo. São Paulo: Martins Claret, (1998); 2002. . The Reasonableness of Christianity (2014).

MARQUES, José Oscar de Almeida. Forçar-nos a ser livres? O paradoxo da liberdade no Contrato Social de Rousseau. Revista Cadernos de Ética e Filosofia Política, Vol. 16, N. 1, 2010, pp. 99-114.

MILL, John Stuart. On Liberty. Ontario: Batoche Books, 2001. . Principles of Political Economy. Ed. Hardpress, 2018.

MORE, Thomas. A Utopia. Edição Bilíngue. Tradução de Márcio Meirelles Gouvêa Júnior. São Paulo: Ed. Autêntica

NEWTON, Isaac. As Profecias do Apocalipse e o Livro de Daniel: As Raízes do Código da Bíblia. São Paulo: Editora Pensamento, 2011. 
PAINE, Thomas. Justiça Agrária. Tradução de Daniel Gomes de Carvalho. Jundiaí: Paco Editorial, 2019.

PARIJS, Philippe Van.; VANDERBORGHT, Yannick. Renda Básica: uma proposta radical para uma sociedade livre e economia sã. São Paulo: Ed. Cortez, 2018.

PINKER, Steven. Enlightenment Now: The case for Reason, Science, Humanism and Progress. London: Penguin Books, 2019.

POGGE. World Poverty and Human Rights: Cosmopolitan Responsibilities and Reforms. Cambridge: Ed. Polity, 2007.

REALE, G.; ANTISERI, D. História da Filosofia Vol. 4. Fortaleza: Ed. Paulus, 2005.

ROUSSEAU, Jean-Jacques. Du Contrat Social. In: Euvres complètes, V.III, Paris: Gallimard, 1966.

RUSSELL, Bertrand. História da Filosofia Ocidental. São Paulo: Nova Fronteira, 2015. SILVA, Walter Guedes da. A Integração do Mercado Brasileiro na Era Vargas e a Colônia Agrícola Nacional de Dourados. In: Revista Geográfica de América Central. Número Especial, 2011, pp. 1-17.

WOLFF, Richard. Democracy at Work. Chicago: Haymarket Books, 2012.

WRAY, Randall. Modern Money Theory: A Primer on Macroeconomics for Sovereign Monetary Systems. New York: Palgrave Macmillian, 2015.

Recebido em: 18/12/2020 | Aprovado em: 02/02/2021 